\title{
PENGARUH PENERAPAN CORPORATE SOCIAL RESPONSIBILITY TERHADAP PERSEPSI NASABAH BANK DAN DAMPAKNYA TERHADAP CORPORATE IMAGE
}

\author{
Muhadjir $^{1}$; Gita Fitri Qurani ${ }^{2}$ \\ ${ }^{1}$ Peneliti pada Balai Besar Riset Sosial Ekonomi Kelautan dan Perikanan \\ ${ }^{2}$ Mahasiswi Universitas Bina Nusantara \\ muhadjir_nasir@yahoo.com
}

\begin{abstract}
The application of corporate social responsibility (CSR) in Indonesia is regulated in UU No. 402007 about company liability on article 74 which mentions the social responsibility to be borne by any corporations. CSR is one of the government's efforts to balance the economic growth and equitability. This study aims to determine how much CSR influences customer's perceptions and its impact on corporate image of BNI. This study uses descriptive-associative method with unit analysis of customers of Bank BNI Fatmawati branch and survey analysis. Data collection uses questionnaires, interviews and literature study of previous researches. Data process uses SPSS 16.0 through validity and reliability, normality test, path analysis, and comparison of the average score through descriptive analysis. The study states that CSR brings effect to corporate image both directly and indirectly through the customer's perception. Therefore, it is expected to continue to maintain BNI social sharing through their CSR programs and enhance public communication, so that the CSR transfer to change the customer's perception leads to a positive success.
\end{abstract}

Keywords: corporate social responsibility, customer's perception, corporate image

\begin{abstract}
ABSTRAK
Penerapan corporate social responsibility (CSR) 'tanggung jawab sosial perusahaan' di Indonesia diatur dalam UU No. 40 Tahun 2007 tentang perseroan Terbatas (PT) pasal 74 yang menyebutkan adanya tanggung jawab sosial yang harus dipikul oleh perseroan terbatas. CSR merupakan salah satu upaya pemerintah menyeimbangkan pertumbuhan ekonomi dan pemerataan ekonomi.Tujuan utama penelitian ini adalah untuk mengetahui seberapa besar pengaruh CSR terhadap persepsi nasabah dan dampaknya pada corporate image Bank BNI. Jenis penelitian ini adalah deskriptif asosiatif dengan unit analisis nasabah Bank BNI cabang Fatmawati dan analisis survei. Teknik pengumpulan data menggunakan kuesioner, wawancara, dan studi pustaka dari penelitian terdahulu. Data diolah menggunakan program SPSS 16.0 melalui uji validitas dan reliabilitas, uji normalitas, analisis jalur, dan perbandingan rata-rata skor melalui analisis deskriptif. Hasil penelitian menyatakan bahwa CSR memberikan pengaruh terhadap corporate image secara langsung maupun tidak langsung melalui persepsi nasabah. Oleh karena itu, BNI diharapkan untuk terus mempertahankan konsep BNI Berbagi melalui program CSR mereka dan meningkatkan komunikasi publiknya, sehingga upaya penyampaian program CSR untuk mengubah persepsi nasabah menjadi positif berhasil.
\end{abstract}

Kata kunci: corporate social responsibility, persepsi nasabah, corporate image 


\section{PENDAHULUAN}

Memasuki tahun 1990-an, semakin banyak perusahaan yang menyadari arti penting dari corporate social responsibility (CSR) 'tangggung jawab sosial perusahaan' dan memasukkannya ke dalam isu strategis bisnis mereka. Berdasarkan berbagai definisi tentang CSR dapat disimpulkan bahwa CSR adalah komitmen dunia usaha untuk terus menerus bertindak secara etis, beroperasi secara legal dan berkontribusi untuk peningkatan ekonomi, peningkatan kualitas hidup dari karyawan serta peningkatan kualitas komunitas lokal dan masyarakat secara lebih luas. Penerapan CSR di Indonesia telah diatur dalam peraturan perundang-undangan, yaitu UU No. 40 Tahun 2007 tentang Perseroan Terbatas pasal 74 yang menyebutkan adanya tanggung jawab sosial yang harus dipikul oleh perseroan terbatas (Republik Indonesia, 2007). Mewajibkan CSR merupakan salah satu upaya pemerintah untuk menyeimbangkan pertumbuhan ekonomi dan pemerataan ekonomi.

Banyak perusahaan semakin menyadari dan menilai pelaksanaan CSR tidak hanya sekedar memenuhi kewajiban seperti yang sudah ditetapkan dalam UU tetapi juga dapat dimanfaatkan (dalam jangka panjang) sebagai sarana untuk dapat memenangkan persaingan dalam industri melalui pembentukan persepsi di benak konsumen sebagai perusahaan dengan image 'citra' yang baik, peduli pada lingkungan dan masyarakat. Penelitian ini menggambarkan program dan kegiatan CSR yang dilakukan oleh PT. Bank Negara Indonesia (PT. Bank BNI). PT. Bank BNI merupakan perusahaan BUMN yang bergerak dalam bidang perbankan dan telah melayani masyarakat sejak tahun 1946. Berdasarkan data, tingkat loyalitas nasabah PT. Bank BNI masih di bawah loyalitas nasabah Bank BCA dan Bank Mandiri (Setiawati, 2011).

Program CSR penting dilakukan guna mendapatkan nilai positif dari nasabah dan berdampak pada corporate image. Namun, apakah program CSR yang sedang dijalankan secara efektif dapat membentuk persepsi nasabah yang positif dan meningkatkan corporate image terhadap Bank BNI? Kajian ini ditujukan untuk mengetahui indikator indikator mana dari kegiatan kegiatan CSR yang dilakukan PT. Bank BNI yang menjadi penentu dalam pembentukan image terhadap perusahaan. Dengan demikian diharapkan dapat menjadi bahan masukan bagi pihak manajemen bank BNI dalam merancang dan melaksanakan program CSR.

\section{Kajian Teoritik}

Iriantara (2004) mengemukakan unsur-unsur dari kegiatan CSR sebagai berikut: (1) continuity and sustainability 'berkesinambungan dan berkelanjutan'. Artinya, kegiatan CSR haruslah dilakukan secara terus menerus dalam jangka panjang, direncanakan dengan sistematis dan dapat diwvaluasi; (2) Community empowerment 'pemberdayaan komunitas'. Artinya, program CSR dilakukan dalam upaya menjadikan komunitas lebih mandiri dibandingkan sebelum adanya CSR; (3) two ways (dua arah), artinya, perusahaan bukan berperan sebagai komunikator semata, tetapi juga harus mampu mendengarkan aspirasi dari komunitas. Ini dapat dilakukan dengan need assesment, yaitu sebuah survei untuk mengetahui needs, desires, interest, dan wants dari komunitas.

Corporate social responsibility (CSR) mempunyai berbagai bentuk tergantung pada kebijakan perusahaan. Sen dan Bhattacharya (2001) mengidentifikasi enam hal pokok yang termasuk dalam CSR yaitu: (1) community support, antara lain dukungan pada program-program pendidikan, kesehatan, kesenian dan sebagainya; (2) diversity, merupakan kebijakan perusahaan untuk tidak membedakan konsumen dan calon pekerja dalam hal gender (jenis kelamin), fisik (cacat), atau ke dalam ras-ras tertentu; (3) employee support, berupa perlindungan kepada tenga kerja, insentif, dan penghargaan serta jaminan keselamatan kerja; (4) environment, menciptakan lingkungan yang sehat dan aman, mengelola limbah dengan baik, menciptakan produk-produk yang ramah lingkungan dan sebagainya; (5) non-U.S operations, perusahaan bertanggung jawab untuk memberikan hak yang sama bagi masyarakat dunia untuk mendapat kesempatan bekerja antara lain dengan membuka pabrik di luar 
negri (abroad operations); dan (6) product, perusahaan berkewajiban untuk membuat produk-produk yang aman bagi kesehatan, tidak menipu, melakukan riset dan pengembangan produk secara berkelanjutan dan menggunakan kemasan yang bisa didaur ulang. Sebuah perusahaan bisa menerapkan salah satu atau seluruh bentuk CSR yang tersebut di atas. Persaingan yang ketat membuat perusahaan berharap bahwa kegiatan CSR ini akan membantu perusahaan untuk memberikan nilai lebih bagi pelanggan dan meningkatkan citra perusahaan. Agar kegiatan CSR ini benar-benar efektif, perusahaan harus mengidentifikasi kebutuhan dan pemahaman masyarakat tentang kegiatan CSR dan juga memperkirakan dengan cermat sumber daya yang dibutuhkan untuk program CSR ini.

Carrol dalam Susanto (2007, p.32) menggambarkan CSR sebagai sebuah piramida, yang tersusun dari tanggung jawab ekonomi sebagai landasannya, kemudian tanggung jawab hukum, tanggung jawab etika dan tanggung jawab filantropis berada di puncak piramida. Tanggung jawab ekonomi adalah memperoleh laba, agar dapat menghidupi karyawan, membayar pajak, dan kewajibankewajiban perusahaan lainnya. Kemudian sebagai perwujudan dari tanggung jawab sosial perusahaan di bidang hukum perusahaan harus mematuhi hukum yang berlaku sebagai representasi dari rule of the game. Tanggung jawab sosial harus tercermin dalam tindakan etis perusahaan, dan kemudian tanggung jawab filantrofis mengharuskan perusahaan untuk berkontribusi terhadap komunitasnya.

Ambadar (2008, p.39), mengemukakan CSR diklaksanakan melalui tahapan tahapan seperti: (1) melihat dan menilai kebutuhan masyarakat sekitar; (2) membuat rencana aksi, lengkap dengan semua anggaran, jadwal waktu, indikator untuk mengevaluasi dan sumber daya manusia yang dapat ditunjuk untuk melakukannya; (3)monitoring, yang dapat dilakukan melalui survei maupun kunjungan langsung. Evaluasi dapat dilakukan agar menjadi panduan untuk strategi atau pengembangan program selanjutnya. Tiga hal yang menjadi fokus perhatian perusahaan dalam melaksananakan tanggung jawab sosialnya adalah: (1) profit, atau laba merupakan unsur yang paling penting dan menjadi tujuan utama dari setiap kegiatan usaha. Profit dapat ditingkatkan melalui peningkatan produktivitas dan melakukan efisiensi biaya, sehingga perusahaan memiliki keunggulan kompetitif yang dapat memberikan nilai tambah semaksimal mungkin; (2) people atau masyarakat yang merupakan salah satu stakeholder yang penting dalam perusahaan, sehingga perusahaan perlu berkomitmen untuk berupaya memberikan manfaat sebesar-besarnya kepada masyarakat (people); (3) planet atau lingkungan yang merupakan sesuatu yang terkait dengan seluruh bidang kehidupan (Susanto, 2007, p.26). Hubungan perusahaan dengan lingkungan adalah hubungan sebab akibat, dimana jika perusahaan merawat lingkungan, maka lingkungan akan memberikan manfaat bagi perusahaan. Dengan kata lain, apa yang perusahaan lakukan terhadap lingkungan tempatnya berada pada akhirnya akan kembali kepada perusahaan sesuai dengan yang dilakukan. (Wibisono 2007, p36)

Pelaksanaan CSR oleh sebuah perusahaan memberikan banyak manfaat (Wibisono, 2007, p.84) diantaranya: (1) mempertahankan atau mendongkrak reputasi dan brand image perusahaan; (2) layak mendapatkan social licence to operate; (3) mereduksi risiko bisnis perusahaan; (4) melebarkan akses sumber daya; (5) membentangkan akses menuju pasar; (6) mereduksi biaya; (7) memperbaiki hubungan dengan stakeholders; (8) memperbaiki hubungan dengan regulator; (9) meningkatkan semangat dan produktivitas karyawan; (10) peluang mendapatkan penghargaan.

Dalam kajian Budiarsi (dalam Saputri, 2010), terdapat beberapa alasan mengapa CSR menjadi sangat penting dalam pembentukkan citra perusahaan. Alasan tersebut yakni, faktor transparansi yang menempatkan perusahaan seakan selalu berada dalam lensa mikroskop sehingga dapat dilihat oleh siapa saja yang menyebabkan siapapun dapat mengetahui aktivitas tangung jawab sosial dengan cepat. Faktor berikutnya yakni pengetahuan dari konsumen dalam memilih produk maupun perusahaan yang tidak hanya mendasari usahanya dari sektor finansial saja, tapi juga faktor sosial dan lingkungan. Faktor yang ketiga adalah keberlanjutan alam semesta. Dan yang terakhir adalah globalisasi dimana era ini masyarakat menginginkan keseimbangan antara keinginan perusahaan dengan keinginan publik yang lebih luas. 
Implementasi kegiatan CSR dapat mempengaruhi persepsi nasabah terhadap suatu perusahaan. Pada penelitian yang dilakukan oleh Poolthong \& Mandhachitara (2008) pada beberapa nasabah Bank di Thailand dijelaskan bagaimana para nasabah semakin percaya dan terpengaruh persepsinya terhadap setiap bank yang melakukan kegiatan CSR. Hasil penelitian membuktikan bahwa CSR berkaitan secara langsung terhadap persepsi nasabah suatu bank. Menurut Bhattacharya (2009) ketika mempersiapkan kegiatan CSR, perusahaan memiliki tujuan untuk meningkatkan persepsi positif terkait dengan kualitas pelayanan dan memberikan tanggapan yang positif dari para stakeholders perusahaan. Holmes (2001) menunjukkan bahwa jika konsumen terlibat langsung dalam kegiatan CSR, persepsi konsumen akan lebih positif terhadap perusahaan. Kegiatan ini dapat membantu perusahaan dalam menjalin hubungan dengan pelanggan dan membangun loyalitas, dan ini telah terbukti memiliki substansial positif berpengaruh pada keuntungan.

Menurut survei yang dilakukan oleh Environics International (Toconto), Confrence Board (New York) dan Prince of Wales Business Leader Forum (London) dalam Dewi (2005), 60\% dari 2.500 responden di 23 negara berpendapat bahwa tanggung jawab sosial perusahaan merupakan salah satu faktor pembentuk citra baik perusahaan. Lebih lanjut, sikap responden selaku konsumen perusahaan terhadap perusahaan yang tidak menjalankan CSR adalah tidak akan membeli produk dari perusahaan yang bersangkutan dan bicara kepada orang lain tentang kekurangan perusahaan tersebut. Survei tersebut cukup menjelaskan bahwa implementasi CSR akan membentuk opini masyarakat dan akan membentuk citra terhadap perusahaan. Akumulasi dari citra perusahaan akan membentuk reputasi yang sangat bermakna bagi perusahaan. Bukan saja bermanfaat dalam hubungan dengan para customer-nya, tetapi juga dengan stakeholder yang lain.

Citra perusahaan diawali dengan persepsi publik dari kegiatan yang dilakukan perusahaan yang dapat membentuk persepsi customer dari waktu ke waktu (Gregory \& Wiechmann, 2001). Terkait dengan ini, Dowling (2001) menyatakan bahwa citra perusahaan mencerminkan persepsi publik tentang tanggung jawab sosial yang dilakukan perusahaan melalui tindakan pemasaran. Lebih jauh Leblanc (2001) menggambarkan citra perusahaan sebagai kesan secara keseluruhan dari pikiran masyarakat terhadap apa yang dilakukan perusahaan. Ini berkaitan dengan atribut fisik dan perilaku berbagai dari perusahaan seperti nama bisnis, arsitektur, berbagai macam produk atau jasa, juga termasuk di dalamnya kegiatan CSR. Citra perusahaan dan reputasi adalah kegiatan sosial yang dibangun melalui dua entitas yang berasal dari persepsi pelanggan.

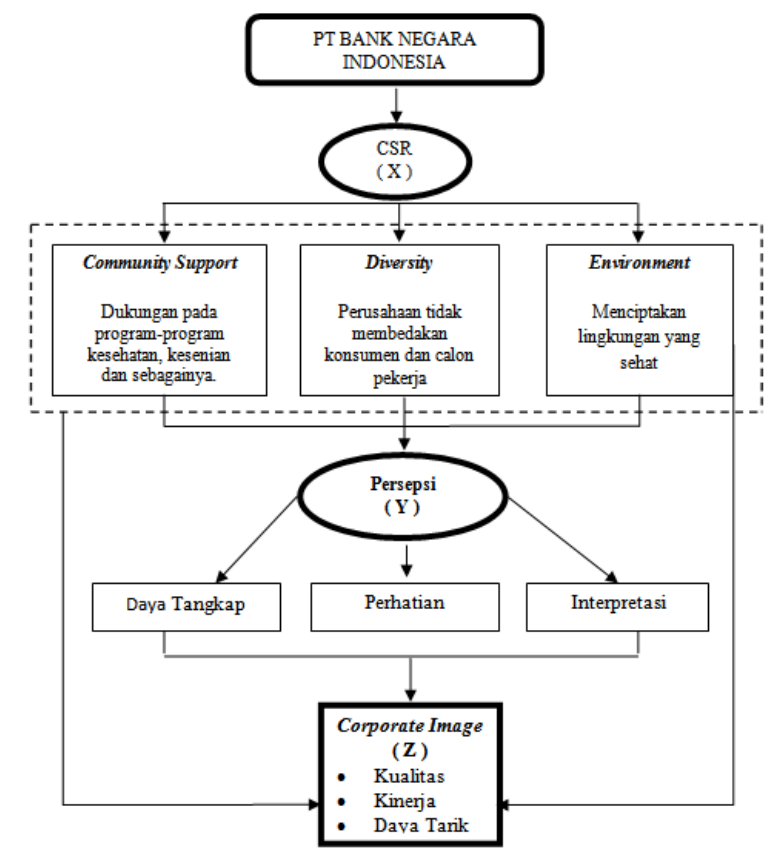

Gambar 1. Kerangka Pemikiran (Sumber: Peneliti, 2011) 


\section{METODE PENELITIAN}

\section{Desain Penelitian}

Desain penelitian (Tabel 1) yang digunakan dalam penelitian ini adalah asosiatif dan deskriptif. Dengan penelitian asosiatif ini dapat diketahui hubungan antara variabel dan bagaimana tingkat ketergantungan antara variabel independen dengan variabel dependen serta variabel intervening. Time horizon yang digunakan adalah cross section di mana data yang dikumpulkan satu kali dalam kurun waktu tertentu. Dalam pelaksanaannya metode penelitian yang dilakukan adalah survei. Unit analisis yang dituju adalah individu, yaitu nasabah Bank BNI Cabang Fatmawati.

Tabel 1 Desain Penelitian

\begin{tabular}{cllll}
\hline TUJUAN & & \multicolumn{2}{c}{ DESAIN PENELITIAN } & \\
\cline { 2 - 5 } PENELITIAN & Jenis Penelitian & Metode & Unit Analisis & Time Horizon \\
\hline T-1 & Deskriptif Asosiatif & Survei & Individu $\rightarrow$ Nasabah & Cross Sectional \\
T-2 & Deskriptif Asosiatif & Survei & Individu $\rightarrow$ Nasabah & Cross Sectional \\
T-3 & Deskriptif Asosiatif & Survei & Individu $\rightarrow$ Nasabah & Cross Sectional \\
T-4 & Deskriptif Asosiatif & Survei & Individu $\rightarrow$ Nasabah & Cross Sectional \\
\hline
\end{tabular}

Sumber: Peneliti, 2011.

Keterangan:

T-1 : Untuk mengetahui bagaimana hubungan corporate social responsibility terhadap persepsi nasabah Bank BNI cabang Fatmawati.

T-2 : Untuk mengetahui bagaimana hubungan corporate social responsibility terhadap corporate image Bank BNI cabang Fatmawati.

T-3 : Untuk mengetahui bagaimana hubungan antara persepsi nasabah terhadap corporate image Bank BNI cabang Fatmawati.

T-4 : Untuk mengetahui bagaimana pengaruh Corporate Social Responsibility terhadap persepsi nasabah dan dampaknya pada corporate image Bank BNI cabang Fatmawati.

\section{Operasionalisasi Variabel Penelitian}

Dalam penelitian ini variabel yang diteliti dibagi menjadi tiga kelompok besar, yaitu variabel bebas (independent variable), variabel perantara (intervening variable) dan variabel terikat (dependent variable) (Tabel 2).

Tabel 2Operasionalisasi Variabel Penelitian

\begin{tabular}{|c|c|c|c|c|c|}
\hline Variabel & Konseptual Variabel & Sub Variabel & Indikator Variabel & Ukuran & $\begin{array}{c}\text { Skala } \\
\text { Pengukuran }\end{array}$ \\
\hline $\begin{array}{l}\text { Corporate Social } \\
\text { Responsibility } \\
\text { (X) }\end{array}$ & $\begin{array}{l}\text { Konsep dimana perusahaan } \\
\text { memberikan perhatian terhadap } \\
\text { masyarakat dan lingkungan } \\
\text { secara terintegrasi dalam } \\
\text { operasi bisnisnya dan didalam } \\
\text { interaksi mereka dengan } \\
\text { stakeholders yang sifatnya } \\
\text { sukarela. }\end{array}$ & $\begin{array}{l}\text { Community } \\
\text { Support }\end{array}$ & $\begin{array}{l}\text { Dukungan pada program: } \\
\text { - } \quad \text { kesehatan } \\
\text { - } \quad \text { pendidikan } \\
\text { - } \text { sarana umum } \\
\text { - } \text { pencana alam } \\
\text { - } \text { bantuan yatim piatu } \\
\text { - } \quad \text { kesenian } \\
\text { - } \text { pemberantasan narkoba }\end{array}$ & $\begin{array}{c}\text { Ordinal } \rightarrow \\
\text { Interval }\end{array}$ & Likert \\
\hline
\end{tabular}




\begin{tabular}{|c|c|c|c|c|c|}
\hline & & Diversity & $\begin{array}{l}\text { perusahaan tidak membedakan } \\
\text { konsumen dan calon pekerja } \\
\text { dalam hal: } \\
\text { - gender } \\
\text { - fisik (cacat) } \\
\text { - } \quad \text { ras-ras tertentu } \\
\text { menciptakan lingkungan yang: } \\
\text { - sehat } \\
\text { - aman }\end{array}$ & $\begin{array}{l}\text { Ordinal } \rightarrow \\
\text { Interval }\end{array}$ & Likert \\
\hline \multirow[t]{2}{*}{$\begin{array}{l}\text { Persepsi Nasabah } \\
(\mathrm{Y})\end{array}$} & $\begin{array}{l}\text { Suatu proses dimana berbagai } \\
\text { stimuli dipilih,di organisir dan } \\
\text { di interpretasi menjadi } \\
\text { informasi yang bermakna. }\end{array}$ & Daya Tangkap & $\begin{array}{ll}\text { - } & \text { kata - kata } \\
\text { - } & \text { gambar } \\
\text { - } & \text { simbol } \\
\text { - } & \text { perhatian nasabah }\end{array}$ & $\begin{array}{c}\text { Ordinal } \rightarrow \\
\text { Interval }\end{array}$ & Likert \\
\hline & & $\begin{array}{l}\text { Perhatian } \\
\text { (Attention ) }\end{array}$ & $\begin{array}{l}\text { terhadap program CSR } \\
\text { - } \quad \text { keingin-tahuan nasabah } \\
\text { - } \quad \text { perhadap program CSR } \\
\text { - } \quad \text { pengkategorian program } \\
\text { - } \quad \text { kesimpulan terhadap } \\
\text { program }\end{array}$ & $\begin{array}{l}\text { Ordinal } \rightarrow \\
\text { Interval } \\
\text { Ordinal } \rightarrow \\
\text { Interval }\end{array}$ & Likert \\
\hline \multirow[t]{3}{*}{$\begin{array}{l}\text { Corporate Image } \\
(\mathrm{Z})\end{array}$} & $\begin{array}{l}\text { Citra perusahaan merupakan } \\
\text { cerminan opini konsumen } \\
\text { terhadap perusahaan. } \\
\text { (Dewi, 2007,p371) }\end{array}$ & Kualitas & $\begin{array}{ll}\text { - } & \text { Kualitas pelayanan } \\
\text { - } & \text { Perhatian kepada } \\
& \text { stakeholder } \\
\text { - } & \text { Kepercayaan dari para } \\
& \text { Stakeholder } \\
\text { - } & \text { Atribut inovasi }\end{array}$ & $\begin{array}{c}\text { Ordinal } \rightarrow \\
\text { Interval }\end{array}$ & Likert \\
\hline & & Kinerja & $\begin{array}{l}\text { - } \quad \text { Prestasi perusahaan } \\
\text { - } \quad \text { Tata kelola } \\
\text { perusahaan }\end{array}$ & $\begin{array}{c}\text { Ordinal } \rightarrow \\
\text { Interval }\end{array}$ & Likert \\
\hline & & Daya tarik & $\begin{array}{ll}\text { - } & \text { Media informasi } \\
\text { - } & \text { Fasilitas }\end{array}$ & $\begin{array}{c}\text { Ordinal } \rightarrow \\
\text { Interval }\end{array}$ & Likert \\
\hline
\end{tabular}

Sumber: Peneliti, 2011

\section{Jenis dan Sumber Data Penelitian}

Jenis data yang digunakan adalah kualitatif menggunakan sumber data primer yang diperoleh dari kuesioner yang dibagikan kepada para nasabah Bank BNI Cabang Fatmawati, dan wawancara terhadap pihak manajemen perusahaan mengenai profil perusahaan Bank BNI Cabang Fatmawati.

\section{Teknik Pengumpulan Data}

Teknik pengumpulan data yang digunakan oleh penulis dalam penelitian ini adalah pertama: studi kepustakaan (library research), dilakukan dengan cara mengumpulkan data, mencatat, mempelajari text book dan buku-buku pelengkap atau referensi, seperti: jurnal dan media cetak lainnya di perpustakaan dan tempat lainnya, serta sumber data lainnya seperti fasilitas internet yang berkaitan dengan permasalahan yang akan diteliti. Studi kepustakaan ini dilakukan untuk mendapatkan informasi yang bersifat teoritis yang akan diteliti sehingga penelitian mempunyai landasan yang kuat sebagai suatu hasil ilmiah. Ke dua, Studi Lapangan (Field Research), dilakukan dengan cara mengumpulkan data primer melalui wawancara dengan responden terpilih menggunakan alat kuesioner tertutup berskala likert.

\section{Teknik Pengambilan Sampel}

Teknik pengambilan sampel yang digunakan adalah teknik probability sampling. Metode penarikan menggunakan sampel secara acak sederhana (simple random sampling). Populasi dalam penelitian ini adalah nasabah Bank BNI Cabang Fatmawati yang berjumlah 119.386 orang. Penentuan jumlah sampel menggunakan rumus dari Tayo Yamane sebagai berikut: 
Keterangan:

$$
\mathrm{n}=\frac{N}{N \cdot d^{2}+1}
$$

$n=$ jumlah sampel

$N=$ jumlah populasi

$d^{2}=$ presisi (ditetapkan $10 \%$ dengan tingkat kepercayaan 90\%)

Dengan data di atas, penghitungan sampel yang digunakan untuk penelitian ini adalah

$$
\mathrm{n}=\frac{119386}{119386 .(0.1)^{2}+1}=99.9 \text { responden }
$$

Dengan demikian sampel yang digunakan sebesar 99.9 responden, dalam penelitian ini sampel dibulatkan menjadi 100 responden.

\section{Teknik Pengukuran Sampel}

Menurut Kuncoro \& Riduwan (2007, p.20) skala likert (Tabel 3) digunakan untuk mengukur sikap, pendapat dan persepsi seseorang atau sekelompok tentang kejadian atau gejala sosial. Dengan menggunakan skala likert, maka variabel yang akan diukur dijabarkan menjadi dimensi, dimensi dijabarkan menjadi sub variabel, kemudian sub variabel dijabarkan lagi menjadi indikator-indikator yang dapat diukur. Akhirnya indikator-indikator yang terukur ini dapat dijadikan titik tolak untuk membuat item instrumen yang berupa pertanyaan atau pernyataan yang perlu dijawab oleh responden.

Tabel 3 Skala Likert

\begin{tabular}{lc}
\hline \multicolumn{1}{c}{ Kategori } & Point \\
\hline Sangat Setuju (SS) & 5 \\
Setuju (S) & 4 \\
Netral (N) & 3 \\
Tidak Setuju (TS) & 2 \\
Sangat Tidak Setuju (STS) & 1 \\
\hline
\end{tabular}

\section{Metode Analisis Data}

Dalam pelaksanaannya, pengolahan data dilakukan dengan bantuan komputer dengan program SPSS (statistical product and service solution) versi 16.0. Data yang sudah dikumpulkan di analisis menggunakan beberapa metode seperti pada Tabel 4.

Tabel 4 Metode Analisis Data

\begin{tabular}{ccc}
\hline \multirow{2}{*}{ Tujuan Penelitian } & \multicolumn{2}{c}{ Metode Analisis } \\
\cline { 2 - 3 } & Jenis Penelitian & Teknik Analisis \\
\hline T-1 & Deskriptif-Asosiatif & Korelasi Pearson \\
T-2 & Deskriptif-Asosiatif & Korelasi Pearson \\
T-3 & Deskriptif-Asosiatif & Korelasi Pearson \\
T-4 & Deskriptif-Asosiatif & Path Analysis \\
\hline
\end{tabular}

Sumber: Peneliti, 2011

Keterangan:

T-1 : Untuk mengetahui bagaimana hubungan corporate social responsibility terhadap persepsi nasabah Bank BNI cabang Fatmawati.

T-2 : Untuk mengetahui bagaimana hubungan corporate social responsibility terhadap corporate image Bank BNI cabang Fatmawati. 
T-3 : Untuk mengetahui bagaimana hubungan antara persepsi nasabah terhadap corporate image Bank BNI cabang Fatmawati.

T-4 : Untuk mengetahui bagaimana pengaruh Corporate Social Responsibility terhadap persepsi nasabah dan dampaknya pada corporate image Bank BNI cabang Fatmawati.

\section{Uji Validitas dan Reliabilitas}

Suatu kuesioner dikatakan valid jika setiap butir-butir pertanyaan pada suatu kuesioner mampu untuk mengungkapkan sesuatu yang akan diukur oleh kuesioner tersebut. Uji pertama pengolahan data sebelum melakukan analisis jalur (path analysis) adalah melakukan uji validitas dan reliabilitas. Data yang dianalisis haruslah reliabel. Sebuah data dapat dinyatakan reliabel jika Cronbach Alpha $>0.600$. Uji pengujian validitas harus dilakukan perhitungan $t_{\text {tabel }}$ dan $r_{\text {tabel. }} . t$ tabel dihitung dengan menggunakan rumus $\mathrm{t}=\mathrm{IDF} . \mathrm{T}(\mathrm{P} . \mathrm{df}$ ), di mana $\mathrm{P}=0,95$ (tingkat kesalahan dianggap $0.5 \% / 0.05)$ dan $\mathrm{df}=30-2$, sehingga diperoleh $t_{\text {tabel }}$ sebesar 1.70 . setelah itu dcari nilai dari $r_{\text {tabel }}$ dengan menggunakan rumus $\mathrm{t} / \mathrm{sqrt}\left(\mathrm{df}+\mathrm{t}^{* *} \mathrm{2}\right)$ dan diperoleh nilai $\mathrm{r}_{\text {tabel }}$ sebesar 0.31 . Pengujian validitas dilakukan pada setiap butir pertanyaan. Syarat suatu butir pertanyaan valid adalah $\mathrm{r}_{\text {hitung }}>\mathrm{r}_{\text {tabel. }}$. Uji reliabilitas dilakukan untuk mendapatkan tingkat ketepatan alat pengumpul data (instrumen) yang digunakan. Uji reliabilitas instrumen dilakukan dengan rumus alpha.

\section{Uji Normalitas}

Distribusi normal merupakan salah satu distribusi yang sering digunakan dalam statistik. Distribusi ini sangat penting, karena banyak sekali uji statistik yang memerlukan data berdistribusi normal. Menguji normalitas data gunanya untuk memenuhi sebagian dari syarat analisis parametrik. Normalitas suatu variabel umumnya dideteksi dengan grafik atau uji statistik. Uji normalitas pada penelitian ini menggunakan alat tes Kolmogorov-Smirnov yang terdapat pada SPSS 16.0 dengan tingkat signifikansi sebesar $0.05 \%$.

\section{Analisis Jalur (Path Analysis)}

Analisis jalur merupakan pengembangan langsung bentuk regresi berganda dengan tujuan untuk memberikan estimasi tingkat kepetingan (magnitude) dan signifikansi (significance) hubungan sebab akibat hipotetikal dalam seperangkat variabel. Analisis jalur sebagai model perluasan regresi yang digunakan untuk menguji keselarasan matriks korelasi dengan dua atau lebih model hubungan sebab akibat yang dibandingkan oleh peneliti.

\section{HASIL DAN PEMBAHASAN}

\section{Profil Responden}

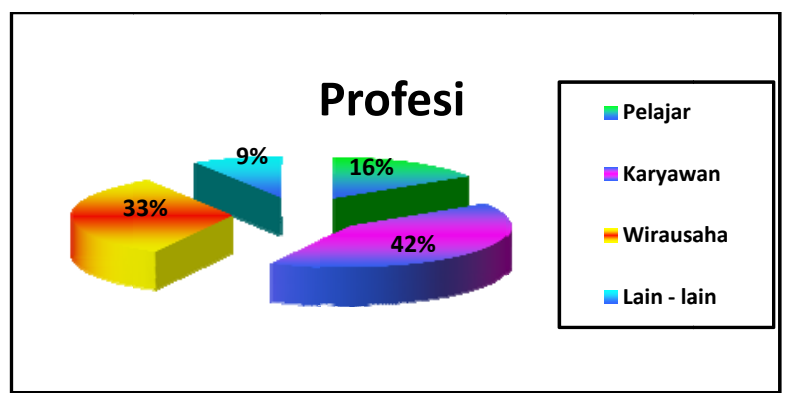

Gambar 2. Profil responden berdasarkan profesi (Sumber: Data Primer, 2011).

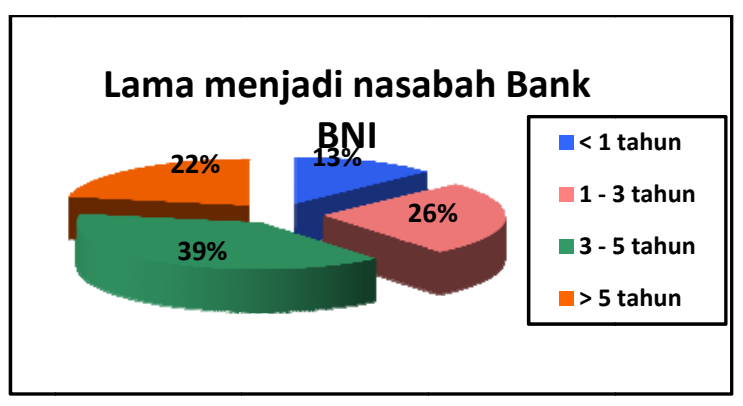

Gambar 3. Profil responden berdasarkan berapa lama menjadi nasabah Bank BNI (Sumber: Data Primer, 2011) 


\section{Hasil Uji Validitas Data}

Berikut ini adalah hasil uji validitas data (Tabel 5).

Tabel 5 Hasil Uji Validitas

\begin{tabular}{|c|c|c|c|c|}
\hline Variabel & Pertanyaan & r Hitung & r Tabel & Keterangan \\
\hline Corporate Social & Butir 1 & 0.675 & 0.31 & Valid \\
\hline \multirow[t]{12}{*}{ Responsibilty (x) } & Butir 2 & 0.556 & 0.31 & Valid \\
\hline & Butir 3 & 0.612 & 0.31 & Valid \\
\hline & Butir 4 & 0.512 & 0.31 & Valid \\
\hline & Butir 5 & 0.323 & 0.31 & Valid \\
\hline & Butir 6 & 0.496 & 0.31 & Valid \\
\hline & Butir 7 & 0.459 & 0.31 & Valid \\
\hline & Butir 8 & 0.663 & 0.31 & Valid \\
\hline & Butir 9 & 0.505 & 0.31 & Valid \\
\hline & Butir 10 & 0.558 & 0.31 & Valid \\
\hline & Butir 11 & 0.381 & 0.31 & Valid \\
\hline & Butir 12 & 0.648 & 0.31 & Valid \\
\hline & Butir 13 & 0.684 & 0.31 & Valid \\
\hline \multirow{8}{*}{$\begin{array}{l}\text { Persepsi nasabah } \\
\text { (Y) }\end{array}$} & Butir 14 & 0.512 & 0.31 & Valid \\
\hline & Butir 15 & 0.438 & 0.31 & Valid \\
\hline & Butir 16 & 0.329 & 0.31 & Valid \\
\hline & Butir 17 & 0.357 & 0.31 & Valid \\
\hline & Butir 18 & 0.492 & 0.31 & Valid \\
\hline & Butir 19 & 0.372 & 0.31 & Valid \\
\hline & Butir 20 & 0.560 & 0.31 & Valid \\
\hline & Butir 21 & 0.154 & 0.31 & Tidak Valid \\
\hline \multirow{14}{*}{$\begin{array}{c}\text { Corporate image } \\
(\mathrm{Z})\end{array}$} & Butir 22 & 0.626 & 0.31 & Valid \\
\hline & Butir 23 & 0.471 & 0.31 & Valid \\
\hline & Butir 24 & 0.460 & 0.31 & Valid \\
\hline & Butir 25 & 0.409 & 0.31 & Valid \\
\hline & Butir 26 & 0.599 & 0.31 & Valid \\
\hline & Butir 27 & 0.420 & 0.31 & Valid \\
\hline & Butir 28 & 0.470 & 0.31 & Valid \\
\hline & Butir 29 & 0.490 & 0.31 & Valid \\
\hline & Butir 30 & 0.484 & 0.31 & Valid \\
\hline & Butir 31 & 0.356 & 0.31 & Valid \\
\hline & Butir 32 & 0.670 & 0.31 & Valid \\
\hline & Butir 33 & 0.475 & 0.31 & Valid \\
\hline & Butir 34 & 0.341 & 0.31 & Valid \\
\hline & Butir 35 & 0.501 & 0.31 & Valid \\
\hline
\end{tabular}

Sumber: Hasil Pengolahan Data, 2011

\section{Hasil Uji Reliabilitas Data}

Berikut ini adalah hasil uji reabilitas data (Tabel 6).

Tabel 6 Hasil Uji Reliabilitas Data

\begin{tabular}{lcc}
\hline \multicolumn{1}{c}{ Variabel } & Cronbach's Alpha & Keterangan \\
\hline Corporate Social Responsibility (X) & 0.867 & Reliabel \\
Persepsi Nasabah (Y) & 0.712 & Reliabel \\
Citra Perusahaan (Z) & 0.840 & Reliabel \\
\hline
\end{tabular}

Sumber: Hasil Pengolahan Data, 2011. 


\section{Hasil Uji Normalitas}

Berikut ini adalah hasil uji normalitas data (Tabel 7).

Tabel 7 Uji Normalitas Data CSR

\begin{tabular}{|l|r|r|r|r|r|r|}
\hline & \multicolumn{3}{|c|}{ Kolmogorov-Smirnov ${ }^{\mathrm{a}}$} & \multicolumn{3}{c|}{ Shapiro-Wilk } \\
\cline { 2 - 7 } & Statistic & Df & \multicolumn{1}{c|}{ Sig. } & Statistic & \multicolumn{1}{c|}{ Df } & \multicolumn{1}{c|}{ Sig. } \\
\hline $\mathrm{X}$ & .075 & 100 & .190 & .986 & 100 & .348 \\
\hline
\end{tabular}
a. Lilliefors Significance Correction
Sumber: Hasil Pengolahan Data dengan SPSS, 2011.

Dari uji signifikansi Kolmogorov-Smirnov di atas, diperoleh sig $=0.190>0.05$, karena itu $H_{a}$ diterima dan $H_{o}$ ditolak. Berarti data untuk variabel x berdistribusi normal.

Tabel 8 Hasil Uji Normalitas Data Persepsi Nasabah

\begin{tabular}{|l|r|r|r|r|r|r|}
\hline & \multicolumn{3}{|c|}{ Kolmogorov-Smirnov } & \multicolumn{3}{c|}{ Shapiro-Wilk } \\
\cline { 2 - 7 } & Statistic & Df & \multicolumn{1}{c|}{ Sig. } & Statistic & \multicolumn{1}{c|}{ Df } & \multicolumn{1}{c|}{ Sig. } \\
\hline $\mathrm{Y}$ & .076 & 100 & .164 & .975 & 100 & .053 \\
\hline
\end{tabular}

a. Lilliefors Significance Correction

Sumber: Hasil Pengolahan Data dengan SPSS, 2011

Dari uji signifikansi Kolmogorov-Smirnov di atas, diperoleh sig $=0.164>0.05$, karena itu $H_{a}$ diterima dan $H_{o}$ ditolak. Berarti data untuk variabel y berdistribusi normal.

Tabel 9 Hasil Uji Normalitas Data Corporate Image

\begin{tabular}{|l|r|r|r|r|r|r|}
\hline & \multicolumn{3}{|c|}{ Kolmogorov-Smirnov $^{\mathrm{a}}$} & \multicolumn{3}{c|}{ Shapiro-Wilk } \\
\cline { 2 - 7 } & Statistic & \multicolumn{1}{c|}{ Df } & \multicolumn{1}{c|}{ Sig. } & Statistic & \multicolumn{1}{c|}{ Df } & \multicolumn{1}{c|}{ Sig. } \\
\hline $\mathrm{Z}$ & .076 & 100 & .170 & .982 & 100 & .201 \\
\hline
\end{tabular}

a. Lilliefors Significance Correction

Sumber: Hasil Pengolahan Data dengan SPSS, 2011

Dari uji signifikansi Kolmogorov-Smirnov di atas, diperoleh sig $=0.170>0.05$, karena itu $H_{a}$ diterima dan $H_{o}$ ditolak. Berarti data untuk variabel z berdistribusi normal.

\section{Analisis Hubungan CSR terhadap Persepsi Nasabah}

Koefisien korelasi antara program corporate social responsibility (x) dengan persepsi nasabah (y) dilakukan dengan menggunakan program SPSS (Tabel 10).

Tabel 10. Hubungan CSR terhadap Persepsi Nasabah

\begin{tabular}{|ll|r|r|}
\hline & \multicolumn{1}{|c|}{ X } & \multicolumn{1}{|c|}{ Y } \\
\hline X & Pearson Correlation & 1 & $.847^{* *}$ \\
& Sig. (1-tailed) & & .000 \\
& $\mathrm{~N}$ & 100 & 100 \\
\hline & Pearson Correlation & $.847^{* *}$ & 1 \\
Sig. (1-tailed) & .000 & \\
N & 100 & 100 \\
\hline
\end{tabular}

**. Correlation is significant at the 0.01 level (1-tailed).

Sumber: Hasil Pengolahan Data dengan SPSS, 2011 
Untuk mengetahui generalisasi dan hubungan variabel CSR terhadap variabel persepsi nasabah Bank BNI Cabang Fatmawati, maka dilakukan uji signifikansi sebagai berikut:

\section{Hipotesis:}

$H_{o:}$ Tidak ada hubungan yang signifikan antara variabel CSR terhadap variabel Persepsi Nasabah. $H_{a:}$ Terdapat hubungan yang signifikan antara variabel CSR terhadap variabel Persepsi Nasabah.

Dari hasil uji signifikan koefisien korelasi untuk satu sisi (one-tailed) dari output pada Tabel 10 menghasilkan angka sebesar 0.00. Jika dibandingkan dengan $\alpha=0.05$, maka nilai Sig lebih kecil dari $\alpha$, artinya $H_{o}$ ditolak atau $H_{a}$ diterima. Dapat disimpulkan bahwa terdapat hubungan yang signifikan antara variabel CSR (x) terhadap variabel persepsi nasabah (y) Bank BNI cabang Fatmawati. Hubungan tersebut masuk kategori hubungan yang sangat kuat (koefisien korelasi $r=$ 0,847). Pengaruh program CSR terhadap persepsi nasabah adalah sebesar $K P=\left(r^{2} \times 100 \%\right)=71.74 \%$..

\section{Analisis Hubungan CSR terhadap Corporate Image}

Koefisien korelasi antara program CSR (x) dengan Corporate Image (z) dilakukan dengan menggunakan program SPSS. Hasil pengolahan korelasi diperlihatkan pada tabel berikut:

Tabel 11 Hubungan CSR terhadap Corporate Image

\begin{tabular}{|c|c|c|c|}
\hline & & $\mathrm{x}$ & $\mathrm{Z}$ \\
\hline \multirow[t]{3}{*}{$\mathrm{X}$} & Pearson Correlation & 1 & $.740^{* *}$ \\
\hline & Sig. (1-tailed) & & .000 \\
\hline & $\mathrm{N}$ & 100 & 100 \\
\hline \multirow[t]{3}{*}{$\mathrm{Z}$} & Pearson Correlation & $.740^{* *}$ & 1 \\
\hline & Sig. (1-tailed) & .000 & \\
\hline & $\mathrm{N}$ & 100 & 100 \\
\hline
\end{tabular}

Untuk mengetahui generalisasi dan hubungan variabel CSR terhadap variabel Corporate Image Bank BNI cabang fatmawati, dilakukan uji signifikansi sebagai berikut:

\section{Hipotesis:}

$H_{o:}$ Tidak ada hubungan yang signifikan antara variabel CSR terhadap variabel Corporate Image. $H_{a:}$ Terdapat hubungan yang signifikan antara variabel CSR terhadap variabel Corporate Image.

Dari hasil uji signifikan koefisien korelasi untuk satu sisi (one-tailed) dari output pada Tabel 11 menghasilkan angka sebesar 0.00. Jika dibandingkan dengan $\alpha=0.05$, maka nilai Sig lebih kecil dari $\alpha$, artinya $H_{o}$ ditolak atau $H_{a}$ diterima. Sehingga dapat disimpulkan bahwa terdapat hubungan yang signifikan antara variabel CSR (x) terhadap variabel Corporate Image (z) Bank BNI cabang Fatmawati. Hubungan tersebut masuk karegori hubungan yang kuat (koefisien korelasi $r=0,74$ ). Pengaruh program CSR terhadap Corporate Image adalah sebesar KP $=\left(r^{2} \times 100 \%\right)=54.76 \%$.

\section{Analisis Hubungan Antara Persepsi Nasabah terhadap Corporate Image}

Koefisien korelasi antara program Persepsi Nasabah (y) dengan Corporate Image (z) dilakukan dengan menggunakan program SPSS. Hasil pengolahan korelasi diperlihatkan pada Tabel 12. 
Tabel 12 Hubungan Persepsi Nasabah terhadap Corporate Image

\begin{tabular}{|c|c|c|c|}
\hline & & $\mathrm{y}$ & $\mathrm{Z}$ \\
\hline \multirow[t]{3}{*}{$\mathrm{Y}$} & Pearson Correlation & 1 & $.772^{* *}$ \\
\hline & Sig. (1-tailed) & & .000 \\
\hline & $\mathrm{N}$ & 100 & 100 \\
\hline \multirow[t]{3}{*}{$\bar{Z}$} & Pearson Correlation & $.772^{* *}$ & 1 \\
\hline & Sig. (1-tailed) & .000 & \\
\hline & $\mathrm{N}$ & 100 & 100 \\
\hline
\end{tabular}

Untuk mengetahui generalisasi dan hubungan variabel Persepsi Nasabah terhadap variabel Corporate Image Bank BNI cabang Fatmawati dilakukan uji signifikansi sebagai berikut:

\section{Hipotesis:}

$H_{o}$ : Tidak ada hubungan yang signifikan antara variabel Persepsi Nasabah terhadap variabel Corporate Image.

$H_{a}$ : Terdapat hubungan yang signifikan antara variabel Persepsi Nasabah variabel Corporate Image.

Dari hasil uji signifikan koefisien korelasi untuk satu sisi (one-tailed) dari output pada Table 12 menghasilkan angka sebesar 0.00. Jika dibandingkan dengan $\alpha=0.05$, maka nilai Sig lebih kecil dari $\alpha$, artinya $H_{o}$ ditolak atau $H_{a}$ diterima. Sehingga dapat disimpulkan bahwa terdapat hubungan yang signifikan antara variabel Persepsi Nasabah (y) terhadap variabel Corporate Image (z) Bank BNI cabang Fatmawati. Hubungan tersebut masuk kategori hubungan yang kuat (koefisien korelasi $\mathrm{r}=$ 0,772). Pengaruh Persepsi Nasabah terhadap Corparate Image sebesar $\mathrm{KP}=\left(\mathrm{r}^{2} \times 100 \%\right)=59.59 \%$.

\section{Analisis Jalur (Path Analysis)}

Langkah pengujian analisis jalur ini dibagi menjadi dua, dimana pengujian dilakukan secara keseluruhan dan individu untuk dua struktur yang dipecah juga menjadi sub-struktur 1 (Tabel 13-15) dan sub-strukur 2 (Tabel 16-18).

\section{Analisis Pengujian Sub-Struktur 1}

Tabel 13 Model Summary Sub-Struktur 1 CSR terhadap Persepsi Nasabah

\begin{tabular}{l|r|r|r|r|}
\hline Model & $\mathrm{R}$ & $\mathrm{R}$ Square & Adjusted R Square & $\begin{array}{c}\text { Std. Error of the } \\
\text { Estimate }\end{array}$ \\
\hline 1 & $.847^{\mathrm{a}}$ & .717 & .714 & .29708 \\
\hline
\end{tabular}
$\begin{aligned} \text { a. Predictors: (Constant), } \mathrm{x} \\
\text { Sumber: Hasil Pengolahan Data dengan SPSS, } 2011\end{aligned}$

Tabel 14Anova Sub-Struktur 1 CSR terhadap Persepsi Nasabah ANOVA $^{\mathrm{b}}$

\begin{tabular}{|ll|r|r|r|r|r|}
\hline Model & & Sum of Squares & Df & Mean Square & F & Sig. \\
\hline 1 & Regression & 21.882 & 1 & 21.882 & 247.938 & $.000^{\mathrm{a}}$ \\
& Residual & 8.649 & 98 & .088 & & \\
& Total & 30.531 & 99 & & & \\
\end{tabular}

a. Predictors: (Constant), $\mathrm{x}$

b. Dependent Variable: y

Sumber: Hasil Pengolahan Data dengan SPSS, 2011 
Tabel 15.Coefficients CSR terhadap Persepsi Nasabah

\begin{tabular}{|c|c|c|c|c|c|c|}
\hline \multirow{2}{*}{\multicolumn{2}{|c|}{ Model }} & \multicolumn{2}{|c|}{ Unstandardized Coefficients } & $\begin{array}{l}\text { Standardized } \\
\text { Coefficients }\end{array}$ & \multirow[b]{2}{*}{$\mathrm{T}$} & \multirow[b]{2}{*}{ Sig. } \\
\hline & & B & Std. Error & Beta & & \\
\hline 1 & (Constant) & .203 & .184 & & 1.107 & .271 \\
\hline & $\mathrm{X}$ & .962 & .061 & .847 & 15.746 & .000 \\
\hline
\end{tabular}

Sumber: Hasil Pengolahan Data dengan SPSS, 2011

Berdasarkan Table 14 di atas, Sig $=0.0000<0.05$ maka dapat diambil kesimpulan bahwa hubungan antara variabel bebas $\mathrm{x}$ terhadap variabel terikat y bersifat linier. Setelah itu, dilakukan analisis jalur terhadap sub-struktur 1 dengan persamaan struktural sebagai berikut: $Y=\rho_{\mathrm{yx}} \mathrm{x}+\rho_{\mathrm{y}} \varepsilon_{1}$

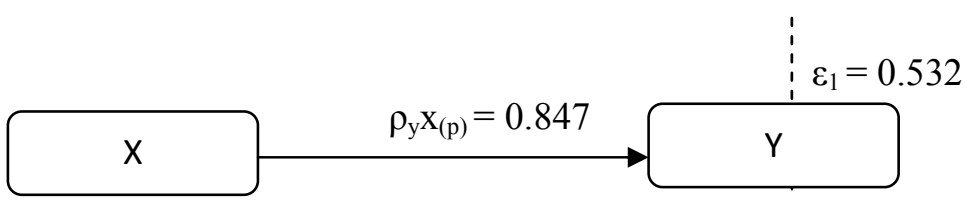

Sumber: Hasil Pengolahan Data, 2011

Gambar 4. Sub-Struktur 1 beserta Koefisien Jalur

\section{Analisis Pengujian Sub-Struktur 2}

Berikut pengujian secara simultan (Keseluruhan) variabel Corporate Social Responsibility (x) serta Persepsi Nasabah (y) terhadap Corporate Image (z).

Tabel 16 Model Summary CSR, Persepsi Nasabah, dan Corporate Image

\begin{tabular}{|l|r|r|r|r|}
\hline Model & \multicolumn{1}{|c|}{$\mathrm{R}$} & \multicolumn{1}{|c|}{ R Square } & Adjusted R Square & $\begin{array}{c}\text { Std. Error of the } \\
\text { Estimate }\end{array}$ \\
\hline 1 & $.789^{\mathrm{a}}$ & .622 & .614 & .31963 \\
\hline
\end{tabular}

Sumber: Hasil Pengolahan Data dengan SPSS, 2011

Tabel 17 Anova CSR, Persepsi Nasabah, dan Corporate Image

\begin{tabular}{|ll|r|r|r|r|r|}
\hline Model & & Sum of Squares & Df & Mean Square & F & Sig. \\
\hline 1 & Regression & 16.292 & 2 & 8.146 & 79.735 & $.000^{\mathrm{a}}$ \\
& Residual & 9.910 & 97 & .102 & & \\
& Total & 26.202 & 99 & & & \\
\end{tabular}

a. Predictors: (Constant), y, x

b. Dependent Variable: $\mathrm{z}$

Sumber: Hasil Pengolahan Data dengan SPSS, 2011 
Tabel 18 Coefficients CSR, Persepsi Nasabah, dan Corporate Image

\begin{tabular}{|c|c|c|c|c|c|c|}
\hline \multirow{2}{*}{\multicolumn{2}{|c|}{ Model }} & \multicolumn{2}{|c|}{ Unstandardized Coefficients } & \multirow{2}{*}{$\begin{array}{c}\text { Standardized } \\
\text { Coefficients }\end{array}$} & \multirow[b]{2}{*}{$\mathrm{T}$} & \multirow[b]{2}{*}{ Sig. } \\
\hline & & B & Std. Error & & & \\
\hline 1 & (Constant) & 1.134 & .199 & & 5.706 & .000 \\
\hline & $\mathrm{X}$ & .321 & .123 & .305 & 2.599 & .011 \\
\hline & $\mathrm{Y}$ & .476 & 109 & .513 & 4.377 & .000 \\
\hline
\end{tabular}

a. Dependent Variable: $\mathrm{z}$

Sumber: Hasil Pengolahan Data dengan SPSS, 2011

Berdasarkan Table 17 di atas, Sig $=0.0000<0.05$ dapat diambil kesimpulan bahwa hubungan antara variabel bebas $\mathrm{x}$, dan $\mathrm{y}$ terhadap variabel terikat $\mathrm{z}$ bersifat linier. Setelah itu, dilakukan analisis jalur terhadap sub-struktur 2 dengan persamaan struktural sebagai berikut: $Z=\rho_{z} x X+\rho_{z y} Y+\rho_{z} \varepsilon_{2}$

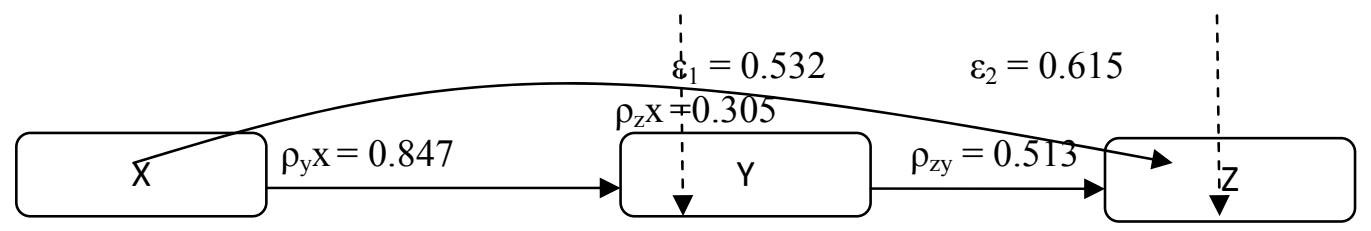

Sumber: Hasil Pengolahan Data, 2011

Gambar 5. Sub-Struktur 2 beserta koefisien jalur.

Keseluruhan hasil analisis jalur terangkum dalam Tabel 19.

Tabel 19 Rangkuman Analisis Jalur

\begin{tabular}{lcccc}
\hline \multirow{2}{*}{ Pengaruh Variabel } & \multicolumn{3}{c}{ Pengaruh Kausal } & \multirow{2}{*}{$\begin{array}{c}\text { Pengaruh } \\
\text { Bersama }\end{array}$} \\
\cline { 2 - 4 } & Langsung & Tidak Langsung & Total & \\
\cline { 2 - 4 } & & Melalui Variabel Y & 0.847 & - \\
X terhadap y & 0.847 & - & 0.739511 & - \\
X terhadap Z & 0.305 & $0.847 \times 0.513=0.434511$ & 0.513 & - \\
Y terhadap Z & 0.513 & - & - & - \\
$\varepsilon_{1}$ & 0.532 & - & - & - \\
$\varepsilon_{2}$ & 0.615 & - & & - \\
\hline
\end{tabular}

Sumber: Hasil Pengolahan Data, 2011

Beberapa hasil pengujian di atas berhasil membuktikan adanya hubungan dan pengaruh antar variabel dependen dan variabel independen serta besaran angka koefisiennya. Namun, jika diteliti lebih jauh terhadap besaran skala angka rata rata pilihan jawaban responden (nasabah) dari masing masing indikator pembentuk variable, beberapa hal yang dapat dibahas adalah: (1) Sebagian nasabah nasabah menganggap bahwa progam CSR BNI tidak maksimal memberikan bantuan kepada masyarakat dalam penyediaan air bersih; (2) Program CSR BNI belum maksimal memberi dukungan terhadap pengembangan dan pelestarian seni dan budaya; (3) Sebagian nasabah nasabah menganggap program CSR BNI belum maksimal memberi dukungan dalam perbaikan sarana dan prasarana umum; (4) Sebagian nasabah belum memiliki pemahaman yang jelas dan menyeluruh terhadap program CSR Bank BNI; (5) CSR yang diadakan oleh Bank BNI belum berperan maksimal untuk dapat diingat oleh nasabah; (6) Penyampaian kegiatan-kegiatan CSR menurut nasabah BNI tidak didukung oleh media informasi yang baik. 


\section{Implikasi Hasil Penelitian}

Berikut beberapa hal menyangkut implikasi penelitian ini.

Pertama, penerapan program Corporate Social Responsibility melalui community support, environment, dan diversity mampu membangun sebuah persepsi nasabah yang positif. Hal ini berarti bahwa jika Bank BNI ingin meningkatkan persepsi positif dari nasabah maka salah satu pilihan yang dapat dipilih adalah dengan meningkatkan dan konsisten dengan penerapan program Corporate Social Responsibility melalui ketiga dimensinya dan konsep CSR yaitu "BNI Berbagi". Kedua, dalam upaya meningkatkan persepsi nasabah yang akan berdampak kepada corporate image, Bank BNI dapat mengembangkan program CSR dengan lebih mendukung pembangunan fasilitas umum dan penyediaan air bersih dengan turut merencanakan, melaksanakan di daerah yang memerlukan bantuan dan membantu meningkatkan pelestarian seni dan budaya. Peningkatan program ini dapat dilakukan dengan meningkatkan kecintaan masyarakat akan budaya Indonesia. Misalnya melalui promosi keindahan batik yang merupakan ciri khas budaya Indonesia, menjadi sponsor dari acara-acara musik dan kesenian tradisional yang diselenggarakan di Indonesia, penggunaan kesenian dan budaya Indonesia dalam iklan-iklan Bank BNI.

Ketiga, dalam upaya meningkatkan pemahaman kepada nasabah, bank BNI dapat melakukan pelatihan karyawan agar dapat memberikan penjelasan yang benar, jelas, dan dimengerti nasabah mengenai pentingnya program CSR yang dilakukan BNI dalam upaya peningkatan kesejahteraan masyarakat Indonesia. Ini akan mendorong persepsi yang positif akan program CSR yang dilakukan oleh Bank BNI. Keempat, edukasi dan pengenalan kepada nasabah mengenai program program CSR perlu ditingkatkan sehingga dapat memiliki posisi yang penting dan nilai tambah dalam ingatan nasabah. Ini akan memberikan dampak yang positif pula terhadap image Bank BNI. Kelima, Bank BNI dapat melakukan riset mengenai media informasi dan media komunikasi apa yang tepat untuk tiap segmen pasarnya dalam mengkomunikasikan kegiatan CSR yang dilakukan.

\section{PENUTUP}

Dari hasil penelitian ini dapat disimpulkan beberapa hal sebagai berikut; (1) Corporate Social Responsibility memiliki hubungan yang sangat kuat, searah dan signifikan dengan persepsi nasabah Bank BNI; (2) Corporate Social Responsibility memiliki hubungan yang kuat, searah, dan signifikan dengan Corporate Image Bank BNI; (3) Persepsi Nasabah memiliki hubungan yang kuat, searah dan signifikan dengan Corporate Image Bank BNI; (4) Terdapat pengaruh yang positif dan signifikan antara Corporate Social Responsibility terhadap persepsi nasabah Bank BNI cabang Fatmawati dan dampaknya pada Corporate Image. Pengaruh ini kuat jika melalui persepsi nasabah jika dibandingkan dengan pengaruh Corporate Social Responsibility terhadap Corporate Image saja.

\section{DAFTAR PUSTAKA}

Ambadar, Jackie. 2008. CSR dalam Praktik di Indonesia. Jakarta: PT. Elex Media Komputindo.

Bank BNI. BNI Annual Report 2010. Diakses dari http://www.bni.co.id/HubunganInvestor/FinancialResult/AnnualReport/tabid/255/Default.aspx

Bhattacharya, Som Sekhar. (2009), Corporate Social Responsibility and Marketing Management: A literature review and perspectives for India. Strategic Innovators, 2 (2). 
Dewi, Kinorika. (2007). Corporate Social Responsibility dan Pengaruhnya pada Good Corporate Image, Jurnal Ekonomi Janavisi, 10 (36), 369-383.

Dowling, G. R. (2001). Creating Corporate Reputations: Identity, Image, and Performance: Oxford: Oxford University Press.

Gregory, J. R., Wiechmann, J. G., (2001). Marketing Corporate Image: The Company as Your Number One Product. New York: McGraw-Hill.

Holmes, Paul (2001). Just Cause. Taking Sides: Clashing Views on Controversial in Marketing. Connecticut: Guilford, McGraw-Hill/Dushkin, 88-96.

Iriantara, Yosal. (2004). Community Relations: Konsep dan Aplikasinya. Bandung: Simbiosa Rekatama.

Leblanc, G., Nguyen, N. (2001) Corporate Image and Corporate Reputation in Customers Retention Decisions in Services. Journal of Retailing and Consumer Services, 8 (4), 227-236.

Poolthong, Y. \& Mandhachitara, R. (2008). Customer Expectations of CSR, Perceived Service Quality and Brand Effect in Retail Banking. International Journal of Bank Marketing, 27 (6), 408427.

Republik Indonesia. (2007). Undang-Undang Republik Indonesia Nomor 40 Tahun 2007 Tentang Perseroan Terbatas. Lembaran Negara Republik Indonesia Tahun 2007 Nomor 106. Jakarta: Sekretariat Negara.

Riduwan, Kuncoro, Engkos Achmad. (2007). Cara Menggunakan dan Memaknai Analisis Jalur (Path Analysis). Bandung: Alfabeta.

Saputri, N. (2010). Analisis Corporate Social Responsibility Sebagai Pembentuk Citra Perusahaan Dan Pengaruhnya Terhadap Loyalitas Pelanggan PT. Fast Food Indonesia di Kota Semarang. Skripsi tidak diterbitkan. Semarang: Universitas Diponegoro.

Sen, S., Bhattacharya, C. B. (2001), Does Doing Good Always Lead to Doing Better? Consumer Reactions to Corporate Social Responsibility. Journal of Marketing Research, 38, 225-243.

Setiawati, D. (2011). 10 Bank yang Memiliki Nasabah Tabungan Paling Loyal. Diunduh 7 Januari 2011 dari http://www.infobanknews.com/2011/01/10-bank-yang-memiliki-nasabah-tabunganpaling-loyal/.

Susanto, A. B. (2007). Reputation Driven Corporate Social Responsibility: Pendekatan Strategic Management dalam CSR. Jakarta: The Jakarta Consulting Group.

Wibisono, Yusuf. 2007. Membedah Konsep dan Aplikasi CSR. Jakarta: Fascho Publishing. 